\title{
Reactive Vascular Proliferation
}

National Cancer Institute

\section{Source}

National Cancer Institute. Reactive Vascular Proliferation. NCI Thesaurus. Code C45479.

A non-neoplastic proliferation of vessels in reaction to a process. 